\title{
Implementation of Strategic Plan in Influencing Academics in Public Teachers Colleges in Tanzania
}

\author{
Molle B Meigaru ${ }^{1 *}$, Dr. Peter Siamoo ${ }^{2}$, Dr. Victorini Salema ${ }^{3}$ \\ ${ }^{1}$ Mwenge Catholic University, 1226 MWECAU Road, Tanzania \\ ${ }^{2}$ Lecturer, Mwenge Catholic University, 1226 MWECAU Road, Tanzania \\ ${ }^{3}$ Senior Lecturer, Faculty of Education, Mwenge Catholic University, 1226 MWECAU Road, Tanzania
}

\begin{tabular}{ll}
\hline DOI: $10.36348 /$ jaep.2019.v03i11.003 & | Received: $01.11 .2019 \mid$ Accepted: $09.11 .2019 \mid$ Published: 12.11 .2019 \\
*Corresponding author: Molle B Meigaru &
\end{tabular}

\section{Abstract}

The study has examined the Influence of strategic planning in improving academics in public Diploma Teachers Colleges in Tanzania. The study used mixed research methods, under concurrent triangulation design. The purpose of using this design was to bring together the differing strengths and non-overlapping weaknesses of quantitative methods with those of qualitative methods. The sample sizes of 10 colleges out of 35 public teachers Colleges with 140 respondents out of the entire population were selected for the research. The study sample comprised 30 Department Leaders, 10 College Principals/Vice Principals and 100 tutors. The study used three sampling techniques which were simple random sampling, stratified random sampling, and convenience sampling. Data were collected through interview guide, document analysis guide; observation and questionnaires and Quantitative data were analyzed through descriptive statistics and presented using frequency, distribution tables, and percentages and inferentially using Pearson correlation. The qualitative data was summarized, coded and analyzed by the research questions. Pilot testing of the research instruments were conducted in one of the teachers' college where the targeted respondents were given a questionnaire and interview guide. The findings of the study revealed that, majority of colleges that had put a strategic plan in place and incorporate students' academic issues had made considerable value-added progress on their students' academic performance.

Keywords: Strategic plan implementation, academic performance, Public Teachers College.

Copyright @ 2019: This is an open-access article distributed under the terms of the Creative Commons Attribution license which permits unrestricted use, distribution, and reproduction in any medium for non-commercial use (NonCommercial, or CC-BY-NC) provided the original author and sources are credited.

\section{INTRODUCTION}

\section{Historical Background of the Strategic Plan in the Education Sector}

Recent years have brought enormous changes in all aspects of life, and educational institutions all over the world have been confronted by dramatic changes in their external and internal environments such as decreasing financial support, rapid technological advances, changing demographics and outdated academic programs. Therefore, many universities and colleges have engaged in strategic planning as a means to make beneficial, strategic changes to adapt to the rapidly shifting environment [1].

Strategic planning in education sector emerged in the United States early in the late 1970s but mainly at the institutional (university and college) level. In the mid-1980s, an estimated 500 districts were practicing some form of strategic planning, and special handbooks were prepared and widely disseminated by professional organizations such as the American Association of
School Administrators (AASA). Strategic planning at the school level was also introduced in many other countries as part of the broader decentralization and school-based management reforms of the late 1980s [2].

The strategic plan in education is used by management to establish objectives, set goals and schedule activities for achieving those goals and includes the methods for measuring progress. These goals can be accomplished through the steps of the strategic plan beginning with an external and internal analysis, a clearly defined mission statement, goals and objectives, formulation of specific strategies, concluding with the implementation of the strategies and managed the control process [3].

\section{Strategic Plan in Tanzania}

In the 1990s the government of Tanzania begins an expansive public sector reform by introducing a strategic plan to all Ministries, Department and Agencies (MDA's). Tanzania's strategic planning, 
budgeting, and reporting processes aim to improve Public Sector performance by: Focusing institutions on the delivery of results; Improving internal decision making; Fostering internal and external accountability, and improving the allocation of resources and ensuring their prioritization.

Strategic planning provides an opportunity to address fundamental questions about the mission of the MDA and undertake bold initiatives and reforms. Nevertheless, the strategic plan creates a basis for decision making and help to create vision and mission for the future with the actual goals and objectives [4].

Nevertheless, the Government of Tanzania has undertaken various structural and institutional reforms, and revises its policies and strategies, and has established several processes aimed at improving service delivery and the general welfare of its citizens. These include, amongst others: the Medium Term Plan (MTP), Sector Strategies, Performance Management Systems, and the Public Expenditure Review (PER) and Medium Term Expenditure Framework (MTEF). These initiatives affect the planning and budgeting as well as monitoring and evaluation taking place within institutions in various ways (Medium Term Strategic Planning and Budgeting Manual, 2005).

In 2005, the government prepared the manual to assist institutions including teachers colleges strategic plan monitoring, evaluation and reporting. The Manual is meant to provide guidance to Ministries, Departments and Agencies (MDAs), Regions and Local Government Authorities on how to prepare Strategic Plan (SPs) and Medium Term Expenditure Framework (MTEF) as well as how to monitor and report on them (Medium Term Strategic Planning and Budgeting Manual, 2005).

\section{Strategic Plan in Public Teachers Colleges in Tanzania}

The fact that Colleges are service-oriented, the Government requires them to make a strategic plan like other business enterprises do to help them to play an important role in the success and survival of all kinds of activities in an organization. The strategic plan aims to improve Teachers' college performance by helps tutors in setting instructional strategies thus increasing student academic achievement.

School Quality Assurance Handbook for Tanzania teachers colleges and schools (2017), direct the quality assurer to assess the extent to which strategic planning documents and action Plans are updated, implemented, shared within the college's community.

Although, the government has introduced a strategic plan to Teachers Colleges for success and survival yet visit inspection report for colleges conducted by quality assurance officers in June 2018 revealed that some colleges failed to prepare the strategic plan on time.

Since the Strategic plan implementation is a good indicator of college performance, Infrastructures and Services in the Teacher Training Colleges reveal neglect, disrepair, deterioration of buildings and furniture [5].

An evaluation study done by the Ministry of Education in all teachers colleges revealed prominent shortages of teaching and learning facilities, infrastructures and services in the Teacher training colleges reveal neglect, disrepair, deterioration of buildings and furniture (MOEST Teachers Colleges Conditional Survey 2016).

Quality education of primary and secondary schools is dependent on quality teachers who depend on quality teachers training colleges. Despite that, colleges are service-oriented; the Government requires them to make a strategic plan to A strategic plan helps the academic achievement. Medium Term Strategic Planning and Budgeting Manual, 2005.

Although, the government introduced a strategic plan to Teachers Colleges for success and survival, visit inspection report for colleges conducted by quality assurance officers in June 2018 revealed that some colleges failed to prepare the strategic plan on time (Quality assurance inspection report for colleges, 2018). Incidentally, while some colleges that have strategic plans were performing better in terms of academic performance, some colleges continued to have poor academic performance despite having a strategic plan.

An evaluation study done by the Ministry of Education in all teachers colleges and visit inspection reports for colleges conducted by quality assurance officers in Northern Eastern Zone Lake and Eastern zone revealed that some colleges were missing an action plan, a very important document that put the strategic plan into action. The visit inspection disclosed poor academic performance with an average of $\mathrm{C}$ and D grade. Quality assurance northern Eastern zone report 2018, Quality assurance Division in Lake Zone report 2018, \& MOEST Teachers Colleges Conditional Survey 2016.

This called for a question of why these situations exist while strategic plan, which is mandatory to all colleges, normally addresses them. A best and well designed and implemented strategic plan is a good indicator of college's progress and development including student academic achievement.

It was perceived that the extent to which each goal of the strategic plan was addressed could have 
implications on the realization of the expected college goals, that is, student-teachers academic performance. That is why this study examined the influence of strategic plan on the academic performance, in the public diploma teachers colleges in Tanzania.

Adetayo [6] examined the impact of strategic planning on organizational performance using a study of selected manufacturing organizations in Lagos, Nigeria. The findings reveal that there is a positive relationship between the use of strategic planning and organizational performance in today's corporate environment while Rhodia [7] investigates the effects of secondary schools' strategic planning on pupils' academic performance in selected schools of Lundazi District in Eastern Province of Zambia. The overall findings indicated that there was a positive and significant influence of the school strategic plan on pupils' academic performance with the greatest influence from teacher preparedness strategy.

Zawadi [8] researched the effect of school strategic plans in enhancing student's academic performance a case of Karatu District in Tanzania. The study explores the effect of the strategic plan on enhancing students' academic performance in Secondary school. Using a case study design, the study employed both qualitative and quantitative approaches with 77 respondents which include 1 district educational officers, 4 head of schools 24 head teachers and 48 students. Data were collected using documentary review, interview, focus group discussion and questionnaire. The sample was selected using purposive sampling and simple random sampling. The study finding reveals that general academic performance for a school that has a strategic plan implemented after school hours and during class periods perform better compare to those who didn't have any effort for implementation apart from the class hour's period.

Mariam [9] researched institutional strategic planning in improving student's academic performance in selected secondary schools in the Dodoma region in Tanzania. There was 98 respondent of the study which included two head of school, 2 academic masters, 2 school board chairpersons, and 12 teachers. The sampling technique was purposive sampling and stratified simple sampling. Data were collected using documentary review, interview, focus group discussion and questionnaire. Findings reveal that there were strategic plans which were implemented after normal class hours and during the free period. The strategic plan was designed by teachers and students and parent is just beneficiaries of the plan.

Though the study focused on the strategic plan which is implemented during the free period and after class hours, the current study focused on the implementation of the strategic plan in influencing academic performance in Diploma Public Teachers Colleges in Tanzania.

Kache [10] researched with the purpose to determine the influence of strategic plan implementation on students' academic performance in public secondary schools in Marsabit Central, SubCounty, Kenya. Four objectives were formulated to guide the study. The study used a descriptive survey design targeting 10 principals, 60 heads of departments and 529 form four students. The sample size was made up of 10 principals, 30 heads of departments and 160 forms four students.

From the study, it was established that the majority of public secondary schools had mission statements written on billboard, walls and entrances. However, they were not always communicated across the school verbally. A majority of schools who had put continuous assessment strategies in place in assessing their students had made a considerable value-added progress on their students' academic performance. The bench-marking strategy was also practiced both internally and externally in some schools. The strategy positively influenced students' academic performance. The schools further use syllabus in schemes of work and lesson preparation, they inform their students about the content of work in each subject area from the syllabus and set targets for syllabus coverage by mid of July. The overall findings indicated that there was a positive and significant influence of schools' strategic plan implementation on students' academic performance with the greatest influence syllabus coverage strategy.

This study assessed aspects of strategic plan implementation in public Secondary schools in Kenya such as mission statement without considering part of the strategy such as implementation strategies and key performance indicators where the current study has assessed those parts. Moreover, it was carried out in context different from Tanzania. The current study covered more than one aspect of strategic plan implementation and it was limited to teachers Colleges in Tanzania.

Gakenia, Katuse and Kiriri [11] conducted a study that sought to examine the role of strategy execution on the performance of national schools. The cumulative effect of strategy execution metrics on academic performance was examined using multiple linear regression analysis. The positive multiple correlation coefficient $(\mathrm{R})$ indicated the cumulative effect of strategy execution is positively correlated to the academic performance of national schools. There is a strong and positive correlation of 0.479 between the strategy execution and academic performance of national schools. On the other hand, the coefficient of determination ( $\mathrm{R}$ Square) of 0.229 indicates that $22.9 \%$ of the variance in academic performance can be 
attributed to strategy execution in national schools. The study though it brings up the positive correlation between strategies execution and academic performance in National, the current study had examined the influence of strategic plan on academic performance in public teachers colleges in Tanzania.

Rodia [12] conducted a study on the effects of the school strategic plan on pupils' academic performance in selected secondary schools of lundazi district, Zambia. The purpose of the study was to investigate the effects of secondary schools' strategic planning on pupils' academic performance in selected schools of Lundazi District. In the Eastern Province of Zambia, schools have formulated smart mission statements and have a three-year strategic plan which is guiding the prioritization of school projects, programs and directing the available resources towards priority targets.

The study had four objectives; to determine the extent to which schools' mission statements influenced pupils' academic performance, to assess how schools' continuous assessment strategy influenced pupils' academic performance, to determine how schools' improving teacher preparedness strategy influenced pupils' academic performance and to establish the extent to which schools' leadership, management, and supervision strategies influenced pupils' academic performance in selected schools of Lundazi District. The study employed a descriptive survey design targeting head teachers, heads of departments, teachers, and pupils. The sample had 3 Head teachers, 15 head of departments, 30 teachers and 120 pupils. The research instruments used were mainly questionnaires and interview guides.

From the study it was established that; the majority of the schools had a mission statement written on school walls and entrances, however, they were not always verbally communicated and explained across the school and as such only influenced pupils' performance to a little extent. Another finding was that schools that had put a continuous assessment program in place in assessing their pupils' made considerable progress to their pupils' academic performance. It was further established that improving teacher preparedness was among the various strategies used by schools and this had positively influenced pupils' academic performance.

The study further revealed that leadership and supervision of teaching and learning strategies influenced pupils' academic performance to a large extent. The overall findings indicated that there was a positive and significant influence of the school strategic plan on pupils' academic performance with the greatest influence from teacher preparedness strategy.
This study focused on the effects of the school strategic plan on pupils' academic performance in selected secondary schools of Lundazi district, Zambia while the current study concentrated on the influence of strategic plan implementation on academic performance in Tanzanian public teachers Colleges. Moreover, the researchers used a descriptive survey design while this study used a mixed-method under concurrent triangulation design.

Gwamukama [13] researched the effect of strategic planning on the academic performance of students at Mbarara University of Science and Technology (MUST) in Uganda. The study wanted to establish how strategic planning affects the academic performance of Mbarara University of Science and Technology. It specifically dealt with establishing the nature of planning, effects of planning and effects of strategic choice on the academic performance of Mbarara University of Science and Technology. The cross-sectional study design was used and a total of 120 respondents sampled, consisting of 11 teachings academic staff, 11 administrative staff, and 90 students. These were purposively and randomly selected and studied. The study was largely qualitative. This was found suitable to get an in-depth investigation of the problem under study. However, quantitative data was also collected and analyzed into simple percentages.

The researcher used semi-structured questionnaires, face to face interviews and documentary reviews to collect the information required in the study. The study found out that remunerations and fringe benefits such as transport facilities, medical care, and accommodation are critical factors for the motivation of employees to enhance academic performance. Strategic intent helped to spell out the field of management at all levels as strategic planning enabled employees to think more clearly about their work in their respective departments.

The strategic choice was found to be a basic, but complex management function. Gwamukama, study focused on the effect of strategic planning on academic performance of students in Mbarara University of Science and Technology (MUST) and use largely qualitative while the current study focused on the implementation of a strategic plan for academic performance in teacher colleges covering three major area which are academic, income-generating projects and infrastructure.

Schlebusch \& Mokhatle [14] conducted a study on Strategic planning as a management tool for school principals in rural schools in the Motheo District in South Africa. The study indicates how strategic management fits into the management process. Strategic planning ensures that the school is associated with the changing internal and external environment. This planning is formulated by top management and 
focuses on the entire organization. A qualitative design was followed in which the opinions of principals were sought through the use of semi-structured interviews.

The findings of the study indicate that strategic planning does not occur in many schools in the Motheo district. If a form of strategic planning does occur, School Governing Body (SGB) chairpersons are often excluded in the drafting and implementation of this plan. Collaboration between School Management Teams (SMTs) and SGBs is needed to ensure the successful drafting and implementation of the strategic plan.

A study on strategic planning as a management tool for school principals in rural schools in the Motheo District focused on the effect of strategic planning on academic performance of students in Motheo District while the current study focused on the effectiveness of strategic plan implementation for performance in teacher colleges covering three major area which are academic, income-generating projects and infrastructure.

None of the study assessed the implementation of strategic plan in influencing student academic performance, infrastructure and income generating projects in diploma teachers colleges in Tanzania.

Therefore, this study investigated the implementation of strategic plan in influencing academic performance in diploma teachers colleges in Tanzania.

\section{RESEARCH DESIGN AND METHODOLOGY}

This chapter presents the methodology of the procedure of collecting and generating data for the study. It presents the research design, target population and describes the sample and sampling techniques. Methods of data collection were identified. Further, the chapter presents the processes which were engaged in the validation of data-gathering instruments. The chapter describes the data analysis procedures and consideration of research ethics.

\section{Research Design}

Research design specifies the methods and procedure for generating data. It can be regarded as a blueprint, a master plan that specifies the methods, techniques, and procedures for collecting and analyzing the needed information or simply a framework or plan of action for the research [15]. The study used a mixedmethod under concurrent triangulation design where the researcher collected and analyzed qualitative and quantitative data on the same phenomenon. In the concurrent design, both qualitative and quantitative data are collected in a single phase with the general aim of obtaining a more developed understanding of the phenomenon under study. The data can be collected from the same participants or similar target populations.
The goal is to get different but complementary data that validate the overall results. Triangulation refers to the use of multiple methods or data sources in research to develop a comprehensive understanding of phenomena [16]. Both qualitative and quantitative data were collected in response to research questions. The intention of using this design was to bring together the differing strengths and non-overlapping weaknesses of quantitative methods, large sample size, trends, generalization with those of qualitative methods, small sample size, details, in-depth [17].

\section{Target Population}

Target population referred to all members who meet the particular criterion specified for a research investigation Caspi [18]. The target population in this study was 35 public teachers Colleges in Tanzania and respondents comprised 35 College Principals/ Vice Principals, 105 department leaders with three representative department leaders from each College and 1, 263 tutors. College Principal/Vice-Principals was included in the study because they were responsible to provide guidance and supervision during the strategic plan process, formulation, implementation, monitoring, and evaluation. Other people participated in the study because of their key role in strategic plan implementation including the academic dean, dean of students and registrars. Academic head, dean of students and registrars are responsible and accountable for setting and advancing the strategy of their Department in line with college strategic plan and direction while tutors are key implementers of strategic plan goals.

\section{Description of sample and sampling procedure}

In this study, the sample consisted of 10 diploma teachers colleges, 10 principal/vice principal, 35 departmental leaders, and 100 college tutors. The study adopted simple random, stratified and convenience sampling to select the respondents. Other respondents were automatically included in the study.

\section{Sampling of Colleges}

The study involved 10 Diploma public teachers colleges out of 35 colleges in Tanzania. Stratified sampling was used to separate colleges into subgroups or strata according to zones (Inspectorate zones), from each of the zonal subgroups created Colleges offering Diploma. The researcher categorized diploma colleges into six inspectorates zone with diploma teachers colleges which were southern lake zone, Western zone, Northern highland, North Eastern, North-western and Southern highland zone. The lottery method of creating a simple random sample was taken from each stratum end up with 10 diploma teacher colleges.

\section{A sampling of Departmental leaders and teachers}

The study sample comprised 30 departmental leaders in 10 colleges, who were, academic deans, 
registrars, and dean of students. Departmental deans were selected automatically to get a sample of the department leaders while 10 tutors who made a total of 100 tutors were selected using convenience sampling depending on the availability and readiness to fill a questionnaire. The researcher sampled the respondents to focus on particular characteristics of a population that were of interest, which enabled him to answer research questions.

\section{A sampling of College Principal/Vice Principals}

College Principal/Vice-Principals were automatically included in the study because there was only one person in each position. The researcher chose top management because they were responsible for influencing the path taken to accomplish a laid goals by defining the positions and task roles, removing obstacles to performance, by enlisting the assistance of group members in setting goals, promoting group cohesiveness and team effort, by increasing the opportunities for personal satisfaction in work performance and by reducing stress and external controls.

\section{A sampling of college tutors}

Convenience sampling (also known as availability sampling) was used to select college tutors due to the availability of each tutor to participate in the study at that specific time. Convenience sampling is a specific type of non-probability sampling method that relies on data collection from population members who are conveniently available to participate in the study. In other words, this sampling method involves getting participants wherever you can find them and typically wherever is convenient.

Description of sample was summarized in the Table-1:

Table-1: Summary of Sample and Sampling procedure

\begin{tabular}{|l|l|l|l|l|}
\hline Target Population & Total number & Sample size & percentage & Sampling procedure \\
\hline Principal/Vice Principals & 35 & 10 & $29 \%$ & Automatic \\
\hline Department Leaders & 105 & 30 & $29 \%$ & Automatic \\
\hline Tutors & 1,263 & 100 & $7.9 \%$ & convenience sampling \\
\hline Colleges & 35 & 10 & $29 \%$ & Stratified sampling \\
\hline
\end{tabular}

\section{Description of data collection instruments}

An instrument is a technique or method of data collection. Data collection instruments refer to devices used to collect data such as questionnaires, tests, structured interview schedules and checklists [19]. This study employed varieties of instruments to facilitate the collection of data. The instruments that were used included: interview guide, questionnaire, observation guide, and document analysis guide.

\section{Questionnaire for departmental leaders}

A self-administered questionnaire was one of the instruments that were used in data collection. A questionnaire designed for department leaders had two sections which were demographic information of the departmental leaders and the second section consisted of Likert scale, open and closed-ended questions to collect information about research questions. Questionnaires were administered to 3 departmental leaders in each college which make a total of 30 respondents. This helped to gather quantitative information concerning the use of strategic planning implementation.

\section{Questionnaire for tutors}

Tutors Questionnaire had two sections which were demographic information of the respondents and the second section aim at collecting quantitative information about research questions. Questionnaires were administered to 10 tutors in each college which make a total of 100 respondents. This helped to gather quantitative information concerning the implementation of strategic planning in influencing organizational performance.

\section{Interview guide for College principals and vice- principals}

The interview guide was administered to college principals/vice-principals to collect information about research questions. The Interview guide for Principal had questions that addressed research questions on the implementation of the strategic plan since the Vice Principal is the supervisor and implementer of the college duties and activities Some of the details needed by the researcher include extent to which organizational leaders were committed to provide directives to support the implementation of strategic initiatives and how far the management motivated to maintain and support the implementation of strategic initiatives. More ever, college principal was asked on the effectiveness of strategic plan in improving academics performance, income-generating projects and infrastructure in Public Teachers Colleges in Tanzania; factors that affect strategic planning implementation in Public Teachers Colleges in Tanzania; and possible ways to address challenges in the implementation of the strategic plan.

\section{Document analysis guide and Observation Guide}

Data were generated from documents and records which were the non-human source (Appendix 4). In this study, data obtained by this method helped to do a comparison between what was found in the strategic plan document (predicted) and the actual implementation. Moreover, the information obtained 
through these documents was triangulated with the information that the tutors and department leaders provided in their questionnaire. The checklist had six items with three columns with rating column Yes, No and N/A. The document which was examined was the strategic planning document and other related document to strategic planning such as action plan and college development plan. Moreover, the observation method was used by the researcher to prove whether infrastructure and projects indicated in the strategic plan documents were implemented.

\section{Pilot testing of Research Instruments}

The subject to be in the pilot testing was similar to those targeted in the actual study. Therefore, employees working in one of the public diploma teacher colleges were contacted to participate in the pilot testing. The pilot testing data were collected using questionnaires and interview guides from 3 departmental leaders, College Principal/Vice-Principal using the same procedures of data collection for respective respondents. The result of pilot testing had helped to find out whether everyone in a sample not only understands the questions, but understands them in the same way. The college that was used for the pilot study was not included in the sample during the actual study.

\section{Validity of the Research Instrument}

Validity is the extent to which the instruments used during the study measure the issues which were intended to be measured $[20,21]$. Content validity was employed in this study. To obtain content validity, this study evaluated the research instrument with experts in one of the public universities and one of the research institutions by conducting interviews, asking them to give their comments on the instrument. Questionnaire and interview questions were distributed to experts. The experts then commented on the questionnaire and interview guide. This helped to identify ambiguous questions in the instruments and be able to re-align them and ensure that the statements were clearly stated in a way that readers can have the proper interpretation of questions intended by the researcher.

\section{Reliability of the Research Instrument}

The reliability of the questionnaire's questions was done through Cronbach's alpha reliability coefficient which enabled the researcher to check for internal consistency of the instruments. In assessing reliability through Cronbach's alpha, authors suggest different levels of acceptance.

Nunnally [22] recommends that an acceptable alpha is between .50 and .60. Panayiotis [23] increased the level of acceptance and considered that the alpha should exceed the minimum of .70 for internal consistency. While different views have been recommended about levels of acceptance, it is generally agreed that an alpha of .70 and over is acceptable. The calculated value of the reliability coefficient of the scale items through SPSS was 0.903 for this study. Qualitative research instruments were ensured through member checking which helped to seek an opinion as to how questions were made easier to understand. The researcher had given questions to the members to seek opinions as to how questions could be made easier to understand and determine accuracy.

\section{Description of the Data Collection Procedure}

The researcher followed all the necessary processes to make sure the government managerial organs were well informed about the data collection. The researcher obtained an introduction letter from Mwenge Catholic University (MWECAU) Postgraduate Director and submitted it to the Permanent Secretary, Ministry of Education, Science and Technology to request the research permit. The research permit from the Permanent Secretary was submitted to College Principals for them to inform the department leaders and tutors who were the respondents of the study instruments. The researcher distributed questionnaires to 30 departmental leaders and interviewed Principals/Vice-principal by asking structured questions and receiving the answers. The researcher wrote the responses at the time of the interview.

The researcher reviewed existing documents which were the strategic plan document, action plan, and college development plan documents. Reviewing of existing documents helped the researcher understood the history, and uses of the strategic plan with comparison to the organization operation. The review of the strategic plan and other related documents revealed a difference between formal statements of the plan and the actual strategic plan implementation.

\section{Description of the Data Analysis Procedure}

Data screenings were performed to make sure that the data collected can be depended on and were not lead to misleading results. The data that was collected from the field using the questionnaires were screened, edited for accuracy, consistency, and completeness. Coding was used to assign a number to each answer thus allowing the transference of data from the questionnaire to Statistical Package for Social Sciences (SPSS). To analyze the quantitative data gathered from the questionnaires, SPSS version 20 was used. This technique was used to screen the data in terms of coding the data, dealing with missing data, analysis of non-response bias, as well as reliability and validity measurements. SPSS was employed to conduct preliminary data analysis and summarized in frequencies, mean, percentages and frequency distribution. Qualitative data analysis involved the identification, examination, and interpretation of patterns and themes in textual data and determined how these patterns and themes helped to answer the research questions at hand. 
Qualitative data were analyzed by starting with the process of preparing and organizing raw data into meaningful units of analysis by clustering raw data into units that shared similar meanings or qualities. Responses were compared and summarized according to the research questions. Furthermore, Responses were coded, and clustered in similar theme categories, to produce meaning. The initial coding helped the researcher identify topics that appeared repeatedly. Narrations emerging from those clusters were interpreted to answer research questions.

\section{Ethical Consideration in Research}

The research was conducted by observing all necessary research rules, regulations, and responsibilities during the preparation and conduction of research in the field. The attention was paid to obtaining a research clearance letter from MWECAU authority, informing the permission of data collection to respondents.

Voluntary participation of respondents in the research was considered and respect for the dignity of research respondents was prioritized. Nevertheless, full permission was obtained from the participants before the study. Respondents participated based on informed consent. The protection of the privacy of research participants was ensured and adequate level of confidentiality of the research data was ensured. Communication about the research was done with honesty and transparency. However, the type of misleading information, as well as the representation of primary data findings in a biased way was avoided.

\section{FINDINGS}

Influence of strategic planning in improving academics in public teacher colleges in Tanzania

Different studies indicated that there was a positive and significant influence of schools' strategic plan implementation on students' academic performance with the greatest influence syllabus coverage [24]. The reason for this research question was to assess the effectiveness of strategic planning in improving academics in Public Teachers colleges in Tanzania. To understand the effectiveness of strategic plan in improving academics in Teachers Colleges, the researcher organized 7 items which were given to departmental leaders to measure various elements on areas of academics where five Likert scale were used to get quantitative data that would help to assess the effectiveness of the strategic planning in improving academics.

Document analysis guide was also used by the researcher where the three years National Examination Result were assessed to compare whether what was indicated in the strategic plan document had caused any academic improvement as measured by the national examinations. Results on the effectiveness of strategic planning in improving academics in public teachers colleges in Tanzania were presented in Table-2.

Table-2: Departmental leader's responses on Effectiveness of strategic planning in improving academics

\begin{tabular}{|c|c|c|c|c|c|c|c|c|c|c|c|c|}
\hline & & \multicolumn{2}{|c|}{ SD } & \multicolumn{2}{|c|}{ D } & \multicolumn{2}{|l|}{$\mathbf{N}$} & \multicolumn{2}{|l|}{$\mathbf{A}$} & \multicolumn{2}{|c|}{ SA } & \multirow[b]{2}{*}{$\begin{array}{l}\text { Mean } \\
\text { score }\end{array}$} \\
\hline & & f & $\%$ & $\mathbf{f}$ & $\%$ & $\mathbf{f}$ & $\%$ & f & $\%$ & $\mathbf{f}$ & $\%$ & \\
\hline i. & $\begin{array}{l}\text { Student's academic performance strategies is clearly } \\
\text { indicated in the strategic plan document }\end{array}$ & 0 & 0 & 1 & 5 & 1 & 5 & 11 & 55 & 7 & 35 & 4.20 \\
\hline ii. & $\begin{array}{l}\text { Effective planning in your college has contributed academic } \\
\text { performance. }\end{array}$ & - & - & - & - & 2 & 10 & 10 & 50 & 8 & 40 & 4.30 \\
\hline iii. & $\begin{array}{l}\text { Department members regularly discuss the implementation } \\
\text { of strategic plan goals and objectives of their department. }\end{array}$ & - & - & 1 & 5 & 4 & 20 & 13 & 65 & 2 & 10 & 3.80 \\
\hline iv. & $\begin{array}{l}\text { Effective Planning has improved teaching and learning } \\
\text { performance in teachers colleges }\end{array}$ & - & - & - & - & 1 & 5 & 12 & 60 & 7 & 35 & 4.30 \\
\hline v. & $\begin{array}{l}\text { At least three workshops, seminars or in-service training } \\
\text { conducted }\end{array}$ & 1 & 5 & 3 & 15 & 5 & 25 & 10 & 50 & 1 & 5 & 3.35 \\
\hline vi. & $\begin{array}{l}\text { department Work Plan for academic performance is a } \\
\text { continuation of your past years' work from your current } \\
\text { Strategic Plan }\end{array}$ & - & - & - & - & - & - & 16 & 80 & 4 & 20 & 4.20 \\
\hline vii. & $\begin{array}{l}\text { There are the key goals for academic performance that your } \\
\text { organization will strive to reach during the next three years. }\end{array}$ & - & - & - & - & 4 & 20 & 10 & 50 & 6 & 30 & 4.10 \\
\hline & Overall mean for effectiveness of strategic planning in improvi & & & & & & & & & & & 4.04 \\
\hline
\end{tabular}

\section{Source: Research Data 2019}

Note: Effectiveness of strategic planning in improving academics is strongly disagreed when $1 \leq M<2$, disagreed when $2 \leq M<3$, neutral when $M=3$, agreed $3<M \geq 4$ and strongly agreed when $M>5$.

Student's academic performance strategies are indicated in the strategic plan document.

The findings in Table- 2 indicated that $60 \%$ of the departmental leaders agreed that student's academic performance was clearly indicated in the strategic plan document and $35 \%$ of the same group strongly agreed that, students' academic performance is indicated in the strategic plan document. This means $90 \%$ which is a greater majority of departmental leaders affirm that student's academic performance strategies are indicated in the strategic plan. The findings reveal that the training and performance of students is the core 
mandate of the teacher's colleges. The school's quality assurance report shows that students' performance on their final exams was at levels $\mathrm{C}$ and $\mathrm{D}$. From the findings where $90 \%$ of the leader agreed that strategies are clearly indicated in the plan document brought doubt that teaching strategies where incorporated into the college's strategic plan but the implementation of the strategic plan was not considered because it is impossible to implement the plan effectively and experience failure.

To triangulate the findings obtained from the departmental leaders, the interview guide on Student's academic performance was administered to the principals.

\section{Principals had this to say:}

"The strategic plan has helped tutors to see and own their responsibility from different angles and adjust their plan according to the needs and it has promoted the commitment of tutors. Through what have already planed, all department, tutors as well as students put their plan into daily basis action to accomplish the strategic plan" (Interview for Principal, 25th March 2019).

One of Principal said:

'Strategic plan provides performance indicators that enhance the tutors and students to work towards attaining the prescribed goals' (Interview for Principal, 25th March 2019).

A statement from the Principal makes it clear that the college's strategic plan plays an important role in assisting tutors in preparing the long and short term academic achievement. It is the responsibility of the tutors and the college community to ensure that the strategic plan is taken into account in their colleges.

\section{Strategic Plan and Its Contribution to Academic Performance}

The findings in Table-2 indicated that $90 \%$ (50\% agreed and $40 \%$ strongly agreed) that effective planning in their colleges had contributed to academic performance. The researcher investigated the National Examinations academic performance from the National Examinations Council of Tanzania to observe students' academic performance progress to colleges that incorporated academic issues in their strategic plan and those which didn't. Results obtained in three consecutive years from 10 diploma colleges revealed that 4 colleges that incorporated academic issues in their strategic plan had positive progress in academic performance compared to those who did not (DSEE2016-2018).

The results have reflected that effective planning have contributed to the academic performance of teachers colleges. Majority of colleges who had put a strategic plan in place and incorporate students' academic issues in their strategic plan had made considerable value-added progress on their students' academic performance. This means that colleges that incorporate academic issues in their strategic plan had an improvement in academic performance compared to those who did not.

\section{Department members regularly discuss the implementation of strategic plan goals and objectives of their department}

The most evident reason to engage regular discussion in strategic planning by staff members is that it provides direction and focus on the way of implementing strategic plan goals. Having a clearly articulated common understanding enables the college to implement a strategic plan that is a literal roadmap for success. According to the findings in Table-2, 65\% agreed and $10 \%$ strongly agreed that department members regularly discuss the implementation of strategic plan goals and objectives while $20 \%$ are neutral and 5\% disagreed. This implies that common discussion of goals in teachers colleges is important not only because they develop creativity and innovation but because they bring people together and encourage them to communicate problems and results. A strategic plan discussion provides management and staff members the roadmap to align the organization's useful activities to achieve set goals. Discussions guide management decision making in determining resource and budget requirements to achieve set objectives thus increasing operational efficiency.

\section{Effective Strategic Plan implementation has improved teaching and learning performance in teachers colleges}

One of the most important principles of good teaching is the need for planning. Planning provides a structure and context for teacher and students, as well as a framework for reflection and evaluation [25]. According to the findings in Table-2, 50\% of department leaders agreed and $40 \%$ strongly agreed that effective strategic plan had led to teaching and learning performance. The responses by department leaders show clearly the importance of effective strategic Plan in ensuring teaching and learning performance in teachers colleges.

A strategic plan helps colleges identify what it intends to achieve when it comes to their student success objectives and organizational goals. A combination of good planning and communication will ensure that all stakeholders including parents, tutors, principals, board members, and community are all striving for the same goals. Bradford [26] declare that plans encourage commitment by showing staff members that their work is essential, part of a larger strategy to help their students succeed. A wellimplemented and communicated plan holds all staff 
accountable for their actions and encourages collaboration. Best of all, strategic planning provides a framework so that the most important priority of the school - Students' educational achievement is taken care of.

Furthermore, Bradford [26]; explained that a strategic plan effectively organizes colleges and their staff by encourages commitment by showing staff members that their work is essential and strategy help colleges to succeed. A college with a strategy can monitor its progress toward key outcomes and evaluate where and how it may have gotten off track. The strategic plan assists a management and staff members with governance decisions and provides direction for the future with a plan in place, the board has a roadmap which it can track, evaluate and modify to facilitate better governance decisions and provide direction for the future of the school.

Nevertheless, a strategic plan increases communication and engagement in large organizations like college so that everyone understands his or her responsibilities and departments are effective in coordinating their efforts. A well-implemented and communicated plan holds all staff accountable for their actions and encourages collaboration. Best of all, the strategic plan provides a framework so that the most important priority of the college which is an educational achievement is taken care of.

\section{At Least Three Workshops, Seminars or In-Service Training Conducted \\ The researcher further required the} respondents to indicate whether in-service training for teachers is regularly conducted according to the strategic plan. On-the-job training of teachers regularly including strategic plan training will help leaders and tutors to gain a deeper understanding of the formulation and implementation of the strategic plan. In-service training improves the work and strategic plan performance.

From the study, 55\% (50\% agreed and 5\% strongly agreed) that at least seminars and workshops were conducted while $20 \%$ disagreed (15\% disagreed and $5 \%$ strongly disagreed). The results of the findings made it clear that above average of the leaders admit that training is taking place. Also, training on how to prepare and implement a strategic plan was not reported. The absence of such training is an indication that the implementation of the strategic plan was not implemented effectively and such fault failed.

College Principals had this to say:

"In-service training for tutors is often conducted, but courses on how to formulate and implement the strategic plan at teachers Colleges were not conducted at all" (Interview for principal, April 2019).
The majority of department leaders indicate clearly that in-service training for teachers is regularly conducted according to the strategic plan. Presence of in-service training of tutors will increase their professional growth of tutors hence the achievements of the students. The Principal statement agrees with Osamwonyi [27] who states that the need for in-service education of teachers cannot be underestimated. It is a necessity in enhancing work performance and motivation of teachers in the field. The absence of inservice training of teachers will retard the professional growth of teachers as well as "missing gaps" between demands and actual achievement levels. On the other hand strategic plan training is to prepare Principals and employees with the skills they need to complete their work tasks both efficiently and effectively and help them reach college main goals.

\section{Department Work Plan for academic performance was developed from the Strategic Plan}

The findings in Table- 2 indicated that $80 \%$ of department leaders agreed and $20 \%$ strongly agreed that department work Plan for academic performance was developed from the strategic plan while none disagreed. This question intended to assess whether colleges management come up with a new plan every year or they use to follow the five-year guiding strategic plan. The finding revealed that the majority of the college's work plan for academic performance was developed from the Strategic Plan. It was previously reported that only $40 \%$ of colleges were found to have a strategic plan for their colleges. The researcher was convinced that the department leader interpreted action plan goals as strategic plan goals. It should be noted that the strategic plan of the institution is the one that carries the long-term goals of the institution.

A strategic plan was developed to help the organization achieve its long-term vision. Conversely, the work plan/operating plan involves the process of deciding what needs to be done to achieve the tactical objectives of the college. Operational/working planning is done to support strategic planning efforts.

Highlighting on the same point, Al Shobaki [28] described that, the strategic plan is a general guide for the management of the organization according to the priorities and goals of stakeholders. The strategic plan does not stipulate the day-to-day tasks and activities involved in running the organization. On the other hand the Operational Plan presents highly detailed information specifically to direct people to perform the day-to-day tasks required in running the organization. Organization management and staff should frequently refer to the operational plan in carrying out their everyday work. The Operational Plan provides the what, who, when and how much: what - the strategies and tasks that must be undertaken; who - the persons who have responsibility of each of the strategies/tasks; when - the timelines in which strategies/tasks must be 
completed; how much - the amount of financial resources provided to complete each strategy/task.

There are key goals for academic performance that the organization strives to reach during the next three years

The researcher in this question sought to find out from the respondents whether the long term plan was available which had key goals for academic performance. Long term goals for academic performance could be traced from the strategic plan. The finding revealed that $50 \%$ of the department leaders agreed and $30 \%$ strongly agreed that there were key goals in the plan for academic performance which their organizations would strive to reach during the following three years.

There was no evidence documented from six colleges that show the availability of long term goals the organization could strive to achieve during the next three years as it was reported by the majority of the department leaders. This could be due to a lack of proper knowledge of goals formulation and implementation according to strategic plan principles. The availability of reliable college's operational goals which were specific to the daily tasks and requirements to run college activities made it easy for tutors to function and to excel within their work environment. Setting goals made it easier to scale and improve academic performance for students.

Despite the external and internal factors affecting students' academic performance, teachers colleges were supposed to establish academic goals in their strategic plan and take initiative to implement it for better performance.

Nukić \& Karl [29] expressed that Strategic planning is necessary to determine the direction for organization's future and determine how best to achieve it. Its primary purpose is to connect three key areas: organization mission - defining your business' purpose, vision - describing what you want to achieve, your plan - outlining how you want to achieve your ultimate goals. It focuses your efforts and ensures that everyone in the organization is working towards a common goal. It also helps the organization to agree on actions that will contribute to business growth; align resources for optimal results; build competitive advantage; engage with staff and communicate what needs to be done and remove uncertainty.

Generally, the findings on the effectiveness of the strategic plan in improving academics in Public Teachers colleges in Tanzania ranked high in both departmental leaders and tutors questionnaire but the results from observation, document analysis guide, and interview shows clearly that, a strategic plan was not effectively used to improve academically in majority of the colleges.
Colleges that have placed their academic programs on the strategic plan have shown a reasonable level of student achievement compared to the colleges which did not include academic issues on their strategic plan. Integrating strategic planning and academic performance is the best way for teachers colleges to ensure their budget allocations and effort for the academic success of their students are appropriately targeted to long-range solutions.

\section{CONCLUSIONS}

Based on the findings of the study the following conclusions are drawn:-

The study concludes that a majority of colleges who had put a strategic plan in place and incorporate students' academic issues had made considerable valueadded progress on their students' academic performance.

\section{RECOMMENDATIONS}

From the conclusions of this study, the following recommendations were made: The findings indicated the need for comprehensive in-service training for all college management and tutors to understand the formulation and implementation of the strategic plan. There is a need for the Ministry of Education Science and Technology, to review and harmonize existing policies on strategic planning in colleges.

Policies should work towards strengthening the use of the strategic plan in colleges with intensive monitoring and supervision. Reviews of literature reveal that strategic plan in other countries was implemented to the primary school level. There is a need to actively involve all stakeholders such as a parent, staff members and college board in strategic planning implementation. The stakeholders play a significant role in strategy implementation in the colleges because they are responsible for the achievement of implementation of the organization's strategies and problem-solving during the implementation phase.

The study recommended that the Ministry of Education Science and Technology should emphasize the role of strategy execution with the view of improving the academic performance of their colleges. This was because the strategy execution had found to have a significant influence on academic performance. Also, the Ministry of education should create a mechanism where the Ministry's strategic plan is linked to teachers' college's strategic plans.

\section{REFERENCES}

1. Alexander, B., Adams, S., \& Cummins, M. (2016). Digital literacy: An NMC Horizon project strategic brief (pp. 1-16). The New Media Consortium. 
Molle B Meigaru et al; J Adv Educ Philos, Nov 2019; 3(11): 393-404

2. UNESCO. (2010). Strategic planning: Concept and rationale Published by: International Institute for Educational Planning.

3. Chih, Y. Y., \& Zwikael, O. (2015). Project benefit management: A conceptual framework of target benefit formulation. International Journal of Project Management, 33(2), 352-362.

4. Paulson, J. A. (Ed.). (2016). African Economies in Transition: Volume 2: The Reform Experience. Springer.).

5. MOEST. (2018). Quality assurance reports from Lake zone, Eastern and Western zone.

6. Nair, L., \& Adetayo, O. A. (2018). A Critique of the Impact Factor and Ramifications of Its Misuse in Plastic and Reconstructive Surgery: The Real Impact of the Impact Factor. Plastic and reconstructive surgery, $142(4), 566 \mathrm{e}-568 \mathrm{e}$.

7. Dahayanake, M. S., Yang, J., Niu, J. H., Derian, P. J., Li, R., \& Dino, D. (2016). U.S. Patent No. 9,249,351. Washington, DC: U.S. Patent and Trademark Office.

8. Emile, J. F., Julié, C., Le Malicot, K., Lepage, C., Tabernero, J., Mini, E., ... \& Allard, M. A. (2017). Prospective validation of a lymphocyte infiltration prognostic test in stage III colon cancer patients treated with adjuvant FOLFOX. European journal of cancer, 82, 16-24.

9. Mariam. (2015). Institutional strategic planning in improving student's academic performance in selected secondary schools in Dodoma region in Tanzania.

10. Kache, S. S. (2018). Influence of strategic plan implementation on students'academic performance in public secondary schools in marsabit central sub-county, Kenya.

11. Gakenia, C., Katuse, P., \& Kiriri, P. (2017). Influence of Strategy Execution on Academic Performance of National Schools in Kenya. IOSR Journal of Business and Management, 19(7), 2540.

12. Rodia, M. T., Ugolini, G., Mattei, G., Montroni, I., Zattoni, D., Ghignone, F., ... \& Solmi, R. (2016). Systematic large-scale meta-analysis identifies a panel of two mRNAs as blood biomarkers for colorectal cancer detection. Oncotarget,7(21), 30295.

13. Gwamukama, P. K. (2014). The effect of strategic planning on academic performance of students in Mbarara University of Science and Technology (MUST). Unpublished masters dissertation. Makerere University, Kampala, Uganda.

14. Schlebusch, G., \& Mokhatle, M. (2016). Strategic planning as a management tool for school principals in rural schools in the Motheo
District. International Journal of Educational Sciences, 13(3), 342-348.

15. Charmaz, K. (2003). Grounded theory Objectivist and constructivist methods, Strategies for qualitative inquiry, 2 nd edition.

16. Carter, R., \& McCarthy, M. (2014). Vocabulary and language teaching. Routledge.

17. Creswell, J. W. (2013). Steps in conducting a scholarly mixed methods study.

18. Caspi, A., Houts, R. M., Belsky, D. W., Harrington, H., Hogan, S., Ramrakha, S., ... \& Moffitt, T. E. (2017). Childhood forecasting of a small segment of the population with large economic burden. Nature human behaviour, 1(1), 0005 .

19. Kok, T. (2013) Adapting or adopting an instrument for your study, School of Educational Studies Universiti Sains Malaysia.

20. Amin, M. E. (2005). Social science research: Conception, methodology and analysis. Makerere University.

21. Joppe, M. (2000). The Research Process. Retrieved February 25, 1998.

22. Nunnally, J. C., \& Bernstein, I. H. (1994). The Assessment of Reliability. Psychometric Theory, 3, 248-292.

23. Panayides, P. (2013). Coefficient alpha: interpret with caution.

24. Solomon, S. (2018). Influence of Strategic Plan implementationon students' academic performance in public secondary schools in central sub-county, Kenya.

25. Cheung, Y. K. E., Song, X., Li, S., Li, Y., \& Zhu, Y. (2019). The CST bounce universe model-A parametric study. SCIENCE CHINA Physics, Mechanics \& Astronomy, 62(1), 10011.

26. Bradford, E. J., Sarullo, M. J., \& Zammit, C. (2017). Integrating Envision Principles in Program Management for Decision Support. In International Conference on Sustainable Infrastructure 2017 (pp. 223-236).

27. Osamwonyi, E. F. (2016). In-Service Education of Teachers: Overview, Problems and the Way Forward. Journal of Education and Practice, 7(26), 83-87.

28. Al Shobaki, M. J., Amuna, Y. M. A., \& Naser, S. S. A. (2017). Strategic and Operational Planning As Approach for Crises Management Field Study on UNRWA.

29. Nukić, I. S̆., \& Karl, B. G. (2018). Importance of strategic planning in culture: the case of music events. in xiv interdisciplinary management research-imr 2018. 